\title{
Should Peer E-Comments Replace Traditional Peer Comments?
}

\author{
Pham Vu Phi Ho
}

Assoc. Prof., BaRia VungTau University, Vietnam, hopvp@bvu.edu.vn

\section{Luong Thi Kim Phung}

Van Lang University, Vietnam, luongthikimphung@vanlanguni.edu.vn

\section{Tran Thi Thuy Oanh}

University of Foreign Languages Studies, The University of Da Nang, Vietnam, tttoanh@ufl.udn.vn

\section{Nguyen Quang Giao}

Assoc. Prof., The University of Da Nang, Vietnam, nqgiao@ac.udn.vn

Many studies in literature have compared peer e-feedback/comments to traditional peer feedback/comments to see whether one medium of providing feedback should replace the other. However, few studies investigated to see whether two modes of commentary activities positively affected the students' writing quality, instead of just comparing one to another. The literature failed to investigate the extent to which each had effects on students' writing skills. The purpose of this study was to fill this gap. The current study employed quasi-experimental research with control and experimental groups to study the issues. Seventy-two native Vietnamese students from two intact classes at Ho Chi Minh City University of Science who had ever obtained this kind of training activities participated in the study. The training procedures for both groups were similar except one conducted face-to-face peer comments on papers and the other on Facebook social network. Data collection was from pre- vs. post-tests rated by inter-raters and analyzed by the ttests of SPSS software. The findings of the study revealed that peer commentary activities of both groups had significant impacts on students' writing quality; however, the peer e-comments outperformed the traditional peer comments.

Keywords: peer e-feedback/comments, face-to-face peer comments, writing quality, traditional peer comments, Facebook-based peer comments

\section{INTRODUCTION}

For the writing teachers in Vietnam, large size of the class acts as a major barrier (Nguyen, Fehring, \& Warren, 2015; Dang, 2010). With 45 to 50 non-English major

Citation: Ho, P. V. P., Phung, L. T. K., Oanh, T. T. T., \& Giao, N. Q. (2020). Should Peer EComments Replace Traditional Peer Comments? International Journal of Instruction, 13(1), 295-314. https://doi.org/10.29333/iji.2020.13120a 
students, teachers undergo drastic challenge to convey feedback on students' writing (Ferris, 2007), and the students are not motivated in learning writing skills (Hung \& Van, 2018). This problem comes into prominence, specially, when teachers have to provide feedback on the drafts written by a large number of students. According to Yusof et al. (2012), the fact that writing teachers are expected to provide comments to students' drafts at every stage of their writing process" (p. 16), coupled with large class size, contributes to writing teachers' overwhelming workload. Large-size classes were considered as not an ideal environment for students to learn a foreign language (Pham \& Nguyen, 2014). Similar to this situation in Vietnam, Pham (2016) found that dealing with big size classes, the writing teachers could not afford to do evaluations to all students' written papers after each training session.

In order to help reduce workload for the teachers, applying peer commentary activities for students to help each other improve writing skills can be a solution to the abovementioned problems. To the teachers, according to Barnard, Luca and Li (2015), employing peer commentary activities in the writing classrooms is a key professional activity in tertiary education. Huisman et al. (2018) claim that writing teachers in higher education usually employ peer commentary activities as an instructional method in each training session. To the students, this kind of activities enables students to be more autonomous and less apprehensive about writing. In other words, peer commentary activities are central to the development of student's learning (Carless et al., 2011). Boud and Molloy (2013) assert that this kind of activity positions learners as having a key role in driving learning, and thus generating and soliciting their own feedback. More specifically, Mendoca and Johnson (1994) posit that peer comments offer students more control over their writing process as they allow students to directly participate in giving comments; as a result, they do not have to solely rely on teacher comments to revise their drafts. On giving comments to their peers, students realize that their peers also encounter similar difficulties as they do, which helps reduce their writing apprehension and increase their autonomy and self-confidence (Curtis, 2001). Furthermore, peer comments can ease teachers' workload. Employed as an instructional strategy, peer feedback/comment activities help lighten writing teachers' workload without interfering in the students' learning process (Yusof et al., 2012). Having students read and comment on each other's drafts means that their successive drafts have fewer mistakes and are more understandable; consequently, their teachers have to spend less time correcting their revised drafts.

However, when implementing peer feedback/comments into writing classrooms, earlier researchers found some problems with these activities. Boud and Molloy (2013) are of the idea that peer feedback/comment activity is a contentious and confusing issue throughout higher education institutions. Carless et al., (2011) state that in the contexts of higher education, it is increasingly difficult to handle peer comment activities effectively. McConlogue (2015) found that students viewed the process of composing peer comments positively; nevertheless, they viewed the receiving comments, on the whole, as negative activities. According to Kelsey and St.Amant (2012), traditional peer comments such as face-to-face oral comments or paper-and-pen peer comments provoke anxiety among peer commenting groups. Also, these kinds of activities are inconvenient 
to students because they need to meet their peers in person to exchange comments. It takes a tremendous amount of time for a piece of writing to be read and commented by all group members if peer comments are exchanged in large groups. Moreover, traditional peer comments require the use of paper, which probably leads to paperwork problems such as losing or forgeting paper (Palmquist, 1993). These problems in the traditional peer comment activities might be in another perspective when peer comment activity is employed in the technological contexts.

In the digital age, technology plays a very important role in the teaching and learning activities, particularly in learning a foreign language, and the students are less dependent on the teachers due to the support of technology (Pham \& Nguyen, 2019). Recently, Facebook has become the most popular networking site in the world (Zuckerberg, 2018) in general. Currently, 59 million Vietnamese people (approximately $63 \%$ of the population) used Facebook (Statista, 2019); and about 75 percent of Vietnamese Facebook users are from 18 to 34 years old. Each Vietnamese user spends about 2.5 hours on Facebook every day, which is twice as much as the time for watching television (Thanh Nien News, 2015).

Facebook, which is considered the most popular platform for online social networking among university students, offers learners an opportunity to interact with classmates, exchange comments on each other's writing synchronously and asynchronously (Majid, Stapa, \& Keong, 2015). Hence, intergrating Facebook into writing class, particularly using Facebook as a platform for students to exchange peer e-comments on each other's writing can potentially enhance the effectiveness of peer comment activities in a writing class. The purpose of this paper is to investigate whether Facebook-based peer comments or peer e-comments should replace the traditional peer comment activities in the writing classrooms.

\section{LITERATURE REVIEW}

According to Karim et al. (2019), traditional classroom is not the only place to impart education any more due to the supports of technology (e-learning). Many previous studies employed Facebook as a platform for peer comment/feedback activities in EFL writing classes to explore its impacts on students' learning attitudes, comments and revisions, and writing outcomes. First, with regard to students' learning attitudes, Hoang and Nguyen (2016), Shih (2011), Yusof, et al., (2012), and Suthiwartnarueput and Wasanasomsithi (2012) found that students usually obtained positive attitudes toward using Facebook for exchanging peer comments in their English writing courses. In other words, when the students expressed good attitudes on applying a tool for studies, they might pay much attention to their learning activities and outcomes. In terms of the quality of comments, Pham (2019) found that working with peer e-commentary activities, students adopted stronger focus on qualified comments to help each other make better revisions. Wichadee (2013) claimed that Facebook-based peer comments mostly focused on the content rather than grammartical errors and comments on content, tenses and spellings were most frequently incorporated into revisions. Yusof, et al., (2012) also found that the students were able to give constructive comments to their peers on Facebook. However, the number of less useful comments provided by the 
students were more than those of useful comments because the students did not receive sufficient training of how to give qualified comments. Training students how to provide qualified comments was an essential issue in the Academic writing classrooms (Pham \& Usaha, 2016; Tuzi, 2004). Finally, regarding the writing outcomes when employed Facebook for students to conduct their commentaries in the writing classrooms, many researchers (Dizon, 2016; Razak \& Saeed, 2015; Suthiwartnarueput \& Wasanasomsithi, 2012; Hoang \& Nguyen, 2016; Shih, 2011; and Yusof, et al., 2012) found that employing Facebook as a platform for peer comment activities would help students improve their writing skills. Some researchers also found that using Facebook for peer comment activities helped students enhance their grammatical accuracy (Suthiwartnarueput \& Wasanasomsithi, 2012; Wichadee, 2013; Dizon, 2016), their writing styles (Razak \& Saeed, 2015), as well as their writing fluency (Dizon, 2016). Below is the conceptual framework illustrating the effects of Facebook-based peer comments on students' writing outcomes.

\begin{tabular}{|c|c|}
\hline Facebook-based peer comments \\
\hline Positive attitudes \\
\hline Focus more on content than local errors comments \\
\hline Writing accuracy improving writing skills \\
\hline Writing fluency \\
\hline
\end{tabular}

Figure 1

Conceptual framework for the study

A big problem found in those studies, except the case of Dizon's (2016), was that most of the studies employed single-group pre-test post-test quasi-experimental study. There was a lack of a control group to measure the effects of different treatments in different conditions. In addition, few studies investigated the effects of Facebook peer comments on low-proficiency level students and non-English major students' writing quality; and whether Facebook-based peer comments are more effective than the traditional ones. This study attempted to fill these gaps to examine whether traditional peer comment activity is still effective and whether Facebook is a better platform for peer commentary activities to replace the other.

Other research studies have made use of different technology facilities to make comparison between traditional peer comments and peer e-comments to figure out whether the more effective one can replace the other (Pham \& Usaha, 2016). Some studies, according to Chen (2016), on electronic peer comments argue that peer ecomments help reduce the threatening atmosphere caused by traditional comments and that the discourse patterns and language use in the e-comments are more flexible than in spoken discourse. Liu and Sadler (2003) also found that peer e-comments using Microsoft Word were not as effective as those in the traditional mode of exchanging peer comments though peer e-comment activities were more appealing. Similarly, Ho (2015) claimed that although the students preferred peer e-comments via Word and online chat to face-to-face peer comments, they found face-to-face peer commenting more effective. Ho and Savignon (2007) claimed that though using features such as 
"Track Changes" and "Spellings \& Grammar" in Microsoft Office was helpful and convenient, they still preferred employing face-to-face peer comments to peer ecomments. $\mathrm{Xu}$ (2007) found that the quality of peer comments in both modes was not significantly different; still, the students expressed no overt preference between the two modes. More specifically, Song and Usaha (2009) revealed that though the students in the traditional commentary group produced more comments than those in the peer ecommentary one, the latter produced more revision-oriented comments to trigger revisions in the subsequent drafts. Furthermore, the writing quality of essays of the students in the peer e-comment group was significantly better than that of the traditional peer comment group.

Similar to the purpose of the current study, Ebadi and Rahimi (2017) conducted a comparative research with two intacts classes, control and experimental group, in Iran to explore the impact of peer e-comments using Google Docs and face-to-face peer comments on EFL learners' academic writing skills. Data collection was from the academic writing task 1 and task 2 of IELTs, and semi-structured interviews on the learners' perceptions towards the impact of peer e-comments on academic writing skills. The study found that both modes of peer comments significantly improved the students' academic writing skills. Furthermore, the peer e-comments outperformed the face-toface peer comments both in the short and long term. Moreover, the study obtained the learners' positive perceptions towards the impact of peer e-comments on academic writing skills.

As stated above, previous studies found different results and students' preferences toward the two modes of peer commentary activities. Liu and Sadler (2003) recommended that peer e-comments and the traditional peer comments should be complementary to each other instead of being mutually exclusive. Ho (2015) also suggested that there should be a balance in the use of the two modes in peer comment activities. However, few of the above studies, except the case of Ebadi and Rahimi's (2017), investigated to see whether two modes of commentary activities affected the students' writing quality, instead of just comparing one to another. Also, the sorts of technology used to train the students' writing skills in those studies were limited to asynchronous facilities. Different technological tools or platform such as social network, which is popular among the students, to integrate into the commentary activities might yield different results.

\section{Research Questions}

1. Do paper-and-pen peer comment and Facebook-based peer comment activities both significantly improve students' writing outcomes?

2. Is there any significant difference between the effects of Facebook-based peer comment activities and paper-and-pen peer comment activities on students' writing outcomes?

\section{METHOD}

Research design plays a crucial role in the success of a study. Appropriate research design guarantees the production of reliable and accurate data while an inappropriately 
designed study does not yield reliable data (Illowsky \& Dean, 2017). The present study was a quasi-experimental study with a pre-test and post-test control group design (Cohen et al., 2007; Creswell, 2009) due to limitations of randomness. Random assignment eliminates all possible systematic differences between participants in different conditions. However, in many cases in social sciences, randomly assigning participants to groups for the sake of research is impractical or even unethical. A quasi-experimental research design involves "the experimental approach but where random assignment to treatment and comparison groups has not been used (Robson \& Kieran, 2016, p. 126). This is a popular approach to quasi-experiments, in which the experimental group and the control group are selected without random assignment.

This research design helped examine the influence of Facebook-based peer comment activities on students' writing quality and present a report of the causal relationship between variables. A pre-test and a post-test were administered at the beginning and at the end of the course respectively to make sure that whether there were any similarities or differences of the students' writing skills before and after the treatment. The independent variables are peer comment activities through the two modes for exchanging peer comments: Facebook versus paper-and-pen, and the dependent variable is students' English writing quality.

\section{Research Context \& Participants}

This study was conducted at Ho Chi Minh City University of Science, which was one of the five constituent universities of Vietnam National University, Ho Chi Minh City. Through its education program, the university aimed to train its students to be professionals in computer skills and a good command of foreign languages. During the first two years at university, students were required to complete four compulsory general English courses from pre- intermediate to intermediate level, each of which lasted 60 hours and was composed of 15 sessions. The course books used for the training were series of "New Cutting-Edge" by Sarah Cunningham and Peter Moor published in 2006. The aim of the English training program is to equip students with essential English skills that enable them to work effectively in an international working environment.

Regarding sampling, the researcher employed a non-probability sampling technique which was convenient sampling. The underlying motivations for employing this sampling technique by most researchers are "easy accessibility, close proximity, availability at a given time, or the willingness to participate" of the members of the target population (Etikan, Musa, \& Alkassim, 2016, p.2). Seventy-two native Vietnamese students, including 40 students in the control group and 32 students in the experimental group, from two intact English-2 classes were conveniently drawn from the population of 1000 freshmen taking English-2 in the second semester of the academic year 2016-2017 for the study. They were non-English major freshmen, aged between 18 and 20. Their English language proficiency level was pre-intermediate, equivalent to A2 in the Common European Framework of Reference for Languages (CEFR). At the time this study took place, they had been trained to write a descriptive paragraph in English-1 and had not been trained in email writing. In their English-2 course, they were to take a total of 60 hours in a semester of 15 weeks long to learn to refine their four English 
skills. With regard to writing skills, they were going to be trained to write an email responding to a written request.

\section{Teaching Method}

An effective writing teaching method requires the incorporation of the insights of different approaches to teaching writing since each approach to teaching writing has it upsides and downsides. Teachers should aim to employ a balanced approach to teaching writing in order to incorporate the positive aspects of approaches and counteract their negative effects. According to Zen (2005, p.196), "professionals in the field are coming to consensus in seeking a more balanced approach than a single best approach to teaching ESL writing". In this study, to teach students to write a responding email the researcher incorporated the features of the process approach and the genre approach, and adapted the paragraph-pattern approach.

Concerning genre approach, the only genre that students were supposed to master after the course was "a responding email". To teach students the knowledge about the context of this writing genre, the researcher drew students' attention to the purpose of a responding email and the social situations in which a writer might write a responding email. Also, in order to provide students with the knowledge about language used in this genre, the researcher made the students aware of the register of an email. The students also learned items of functional language necessary for writing a responding email.

To familiarize students with the structure of a responding email, the researcher designed some tasks adapted from the paragraph-pattern approach. In these tasks, students were required to analyze the organization of a model responding email, unscramble sentences to make a complete appropriate email, or write a sentence in the gap to complete a responding email. These task types also helped the students to learn the features of a responding email in English.

So as to help students practice the writing skills, the researcher required the students to follow four steps in the writing process: prewriting, drafting, revising, and editing (Badger \& White, 2000). In the prewriting step, the students were encouraged to discuss, brainstorm for ideas and make a rough outline of their responding email. In revising and editing steps, the students were assisted by peer comments and teacher comments.

\section{Training in Peer Commenting Activities}

The size of peer commenting groups in this study was paid meticulous attention by the researcher. Liu and Hansen (2002, p. 62) posits that "the size of the group is a variable that could affect any group work." Also, they stated that it depends on many variables such as the essence of the tasks, time limit for the tasks, the students' levels of proficiency and their maturity. The current study assigned the students of both control and experimental groups to work in groups of four members. This number of members was relatively small, ensuring the students overcame the drawbacks of large groups, but it was the bigger minimum member of each group, which is three members in a group, in order to make sure each group still ran efficiently if a member of a group either dropped 
out of the course or quit the peer commenting activities. Also, students stayed in the same peer commenting groups across the semester so as to keep building on their knowledge of their group members.

Although the number of students in all peer commenting groups was the same in both control and experimental groups, the way the researcher assigned students into groups in the control group and in the experimental group differed. In the control group, peer commenting groups were self-initiated, which means students were allowed to form groups based on their convenience. This made sure all students got along with each other in their groups and they could meet easily after class for peer commenting activities. In the experimental group, the teacher created a Facebook group and ensured all participants in the experimental group joined the Facebook group. Students then were assigned to peer commenting groups randomly according to alphabetical order of their names in the class list. This was because students in these peer commenting groups were required to exchange peer comments through an asynchronous platform which is Facebook, so proximity and personality differences were less likely to affect their peer commenting activities.

Training students to give peer comments is key to figuring out the effects of peer commenting activities, if there are any, on students' writing quality. According to Liu and Hansen (2002, p.122), 'instruction in peer response is vital in forming students' perceptions toward peer response activities, the types of responses they make, and the extent to which they incorporate their peers' suggestions into their papers". If the students are not carefully instructed how to use the peer comment guidelines effectively, and what steps to follow in the peer commenting process, peer comment activities can be quite confusing and tiring to them.

In this study, in order to guide the students to perform peer commenting activities, the teacher/researcher first explained the purposes of the activities, and then instructed them to write a responding email. Next, the researcher provided the students with the guidelines, explained the details in the guidelines and demonstrated to them how to use the guidelines to give peer comments (see fig. 1). After that, the students had two weeks to exchange peer comments in their groups. Then, an in-class conference was held so that the teachers could make sure the students followed the required steps. Also, according Liu and Hansen (2002, p.127), in order to ensure students' responsibility for giving peer comment activities, teachers "should read peer comments and give students credit for their comments". In this study, the students were informed in advance that their comments would be read and marked by the teacher. 

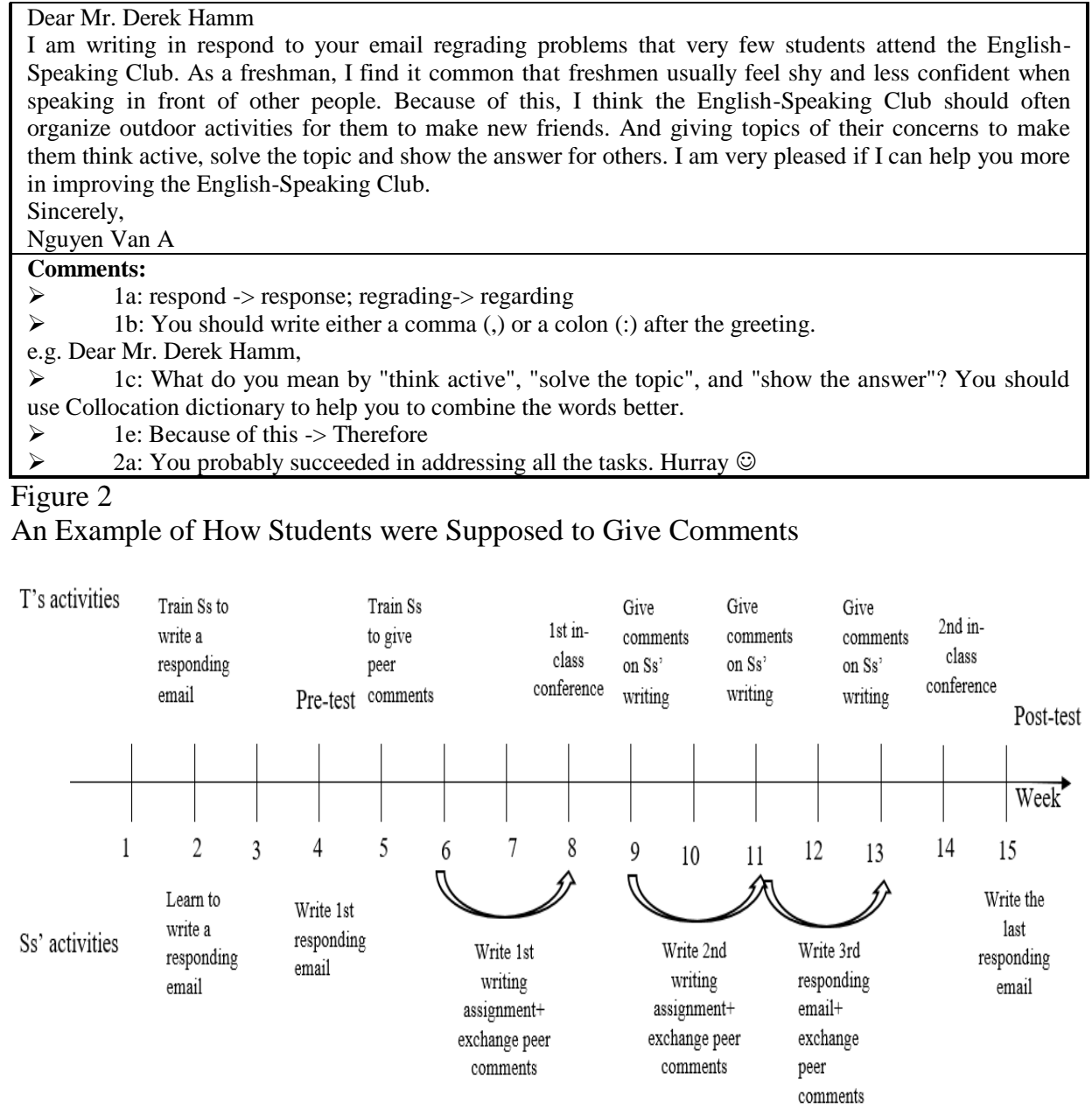

Figure 3

Procedures of Peer Comment and Teacher Comment Activities

The 15-week semester of the current study took place from 24/2/2017- 2/6/2017 including 15 in-class sessions and homework for both the students and the teacher. Week 1, the teacher familiarized the students with a new genre: email. The students were also trained to differentiate formal from informal registers and to be aware of the target readers of their emails. From week 2 to week 3, the students were trained to write a responding email including its format and functional language used in a responding email. Both control and experimental groups received similar writing instructions. Week four, a pre-test, in which students were asked to write a responding email, was 
administered to the students. The researcher had the students in both groups write an email responding to a written request in class for twenty minutes using pens and paper. They were not allowed to use any electronic device when taking the pre-test. The researchers paid careful attention to the conditions under which the pre-test was administered to ensure they were the same for both the control and the experimental groups. Students' writings were then collected and coded before being given to the two inter-raters.

Week 5, the teacher trained the students to give peer comments using guidelines for peer comments. From week 6 to week 8 , students were asked to (1) write the first writing assignment in class, (2) revise their first drafts at home and either exchange peer comments face-to-face using pen and paper if they belonged to the control group or exchange their peer comments on the Facebook group if they belonged to the experimental group, (3) redraft their writing after receiving peer comments, and (4) hand in their writing to the teacher in order to receive her comments. Also, in week eight, an in-class conference was held to make sure students followed the Guidelines for peer comments. According to Liu and Hansen (2002), because teachers are those who determine students' grades, they have power over students, so teachers' comments usually carry more weight than peers' comments. That is why in this study, the teacher intentionally asked students to exchange peer comments before they handed in their drafts to the teacher for her comments. This process was repeated from week nine through to week 13, in which students were asked to write the second and third writing assignments, exchange peer comments among their groups, and revise their drafts after receiving peer comments. In week 14 , the second in-class conference was held so that teachers could correct students' typical mistakes in class. In week 15, a post-test was administered to all the participants.

\section{The Writing Cycle of the Training}

Two English-2 classes taught by the teacher/researcher were chosen to participate in this study. The participants were notified that their work during the course would be analyzed for the purpose of this research. To make this research possible, the researcher created a Facebook Group and she ensured that all students in the experimental group joined the Facebook group.

For each writing assignment, the researcher followed the writing cycle (see Fig. 3). Each writing cycle lasted two weeks. First, the teacher introduced the writing topic to both groups. She also familiarized the students with the topic and vocabulary related to the topic. She also instructed the students to outline their responding emails. Then, the students were asked to write the first writing assignment in class on a piece of paper. Next, they were asked to revise their drafts before exchanging their drafts for peer comments. After that, Facebook based-peer comment activities were administered to the experimental group, which meant the students in the experimental group had to post their writing on the Facebook group for their friends to comment on, while students in the control group were asked to write their comments on paper and meet in person to exchange peer comments. Next, all students in both groups were asked to revise their drafts and either hand in their second drafts to the teacher if they belonged to the control 
group or post their second drafts on the Facebook group if they belonged to the experimental group. For the control group, the teacher read and commented on the student drafts by correcting their mistakes and writing comments on paper. For the experimental group, the teacher commented by typing her comments in the "Comment Section" immediately below the students' posts on the Facebook Group. Finally, all the students were made to revise their drafts and write the final drafts.

This cycle was repeated three times corresponding with the three writing assignments during the course.

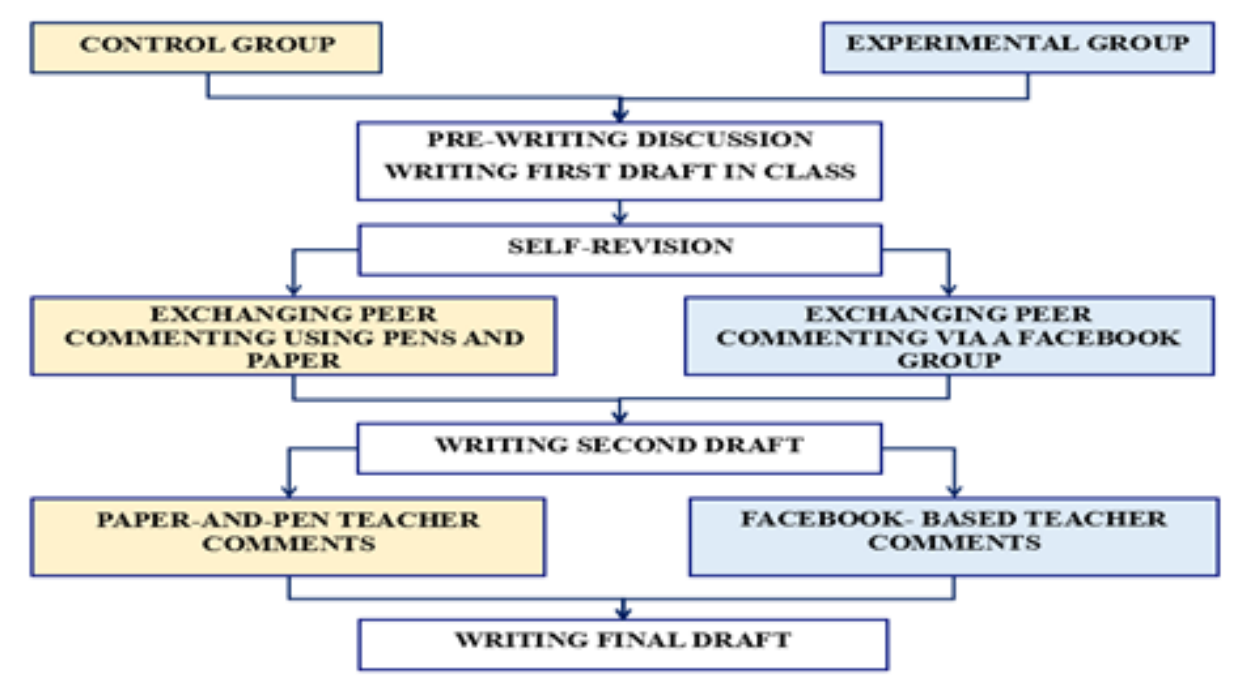

Figure 4

The Writing Cycle for Each Writing Assignment of Both Groups

Tests

Most EFL students' writing skills are usually assessed through the production of written assignments. According to Hyland (2016), tests elicit performance information from students, so offer insights into students' writing ability. Thus, variable writing quality in this study was measured by the scores that the participants achieved in their pre-test and post-test.

The requirements of the pre-test and post-test were similar in terms of the format and topics: The participants were asked to write an email applying for a job in response to a job advertisement. The interval between the pre-test and post-test was ten weeks.

In the fourth week of the course, when the students had been instructed how to write a responding email but did not start peer commenting activities, a pre-test was administered to both control and experimental groups. The two groups did the same test whose requirements were about writing an email applying for a temporary summer job 
in response to a job advertising email. The twenty- minute time limit was imposed on both groups. The students from both groups were asked to do the pre-test using pens and paper. In the fifteenth week of the course, a post-test was administered to the two groups. The teacher ensured students from both groups did the post-test under the invigilation that was similar to that of the pre-test. The post-test for the control group and experimental group was similar in terms of topic and difficulty level. Both control group and experimental group were asked to write an email applying for a job corresponding to the majors that they were studying at university in response to a job advertisement email.

\section{Scoring rubric}

Since the task of writing an email responding to a written request is a writing task in a TOEIC writing test developed by ETS (Educational Testing Service), an American educational testing and assessment organization, ETS offers a 5-band scoring rubric from 0 to 4 for marking this writing task. However, teachers in Vietnam are familiar with awarding students a wider score range which is from 0 to 10. Thus, IIG Vietnam, which is a representative of many world organizations including ETS in Vietnam, developed an 11-band scoring rubric from a 5-band scoring rubric of ETS for marking this writing task and use it in their training program.

In this study, the 11-band scoring rubric of IIG Vietnam was used to mark students' papers in the pre-test and post-test because of two reasons. First, most teachers in HCMC US were trained by IIG Vietnam to use this scoring rubric to mark students' papers while they had no experiences in marking students' papers using ETS' scoring rubric. In addition, Vietnamese teachers are more familiar with an 11-band scoring rubric than a 5-band rubric, which is conducive to a higher level of reliability of the test results. Second, many researchers agree that the more specific the scoring rubric is, the better test results a researcher gets. Researchers should make the scoring rubric as detailed and specific as possible, such as giving students specific points for each item (Cohen et al., 2007). In fact, "the more marks that are available to indicate different levels of achievement (e.g. for the awarding of grades), the greater the reliability of the grades will be" (Cohen et al., 2007, p. 430). The scoring rubric used in the study is an analytic scoring rubric including four criteria for marking students writing, namely quality and variety of sentences, vocabulary, organization, and task completion. On marking student's writing, the inter-raters award a score ranging from 0 to 10 for each criterion, and then combine the four individual scores into a single score by calculating the average.

\section{Inter-rating students' writing}

The two inter-raters who participated in this study were the researcher's colleagues working as a teacher of English at HCMC University of Science. They both graduated from Faculty of English Linguistics and Literature, HCMC University of Social Sciences and Humanities, and are currently pursuing a Master's degree in TESOL at HCMC USSH. Both of them had been trained to use the scoring rubric by IIG Vietnam before participating in this study. 
After collecting data from the 15-week training course, the researcher met the interraters in order to explain the aims and the design of the current study. Then, a hard copy of the scoring rubric and copies of students' pre-test and post-test papers were given to each inter-rater. Also, students' names on their papers were coded so that their real names were completely unknown to the inter-raters to ensure their impartiality in marking the papers. After receiving the test scores from the two inter-raters, the researcher inserted the test scores from the two inter-raters into a Microsoft Excel document. If the discrepancy in the scores of two inter-raters was no more than 1 point $(\leq 1)$, the final score would be the average of the two scores. If the difference between the two scores of the two inter-raters was more than 1 point, the researcher would mark that test, and the final score would be the average of the scores given by the researcher and one of the two inter-raters whose score was closer to that of the researcher. The scores in seven papers from the two inter-raters were consistent, most of the other were different by .5 or 1.0 point. The researcher had to mark 14 papers because the discrepancy in the scores was more than 1. Pearson Correlation coefficient was computed to assess the correlation of the scores marked by the two inter-raters and the researcher. The results are that the correlation coefficient between the control group's pre-test scores is $r=.729, p=.000$; the correlation coefficient between the control group's post-test scores is $r=.868, p=.000$; the correlation coefficient between the experimental group's pre-test scores is $r=.808 ; p=.000$; and the correlation coefficient between the experimental group's post-test scores is $r=.840 ; p=.000$. These results indicate that the writing scores have good correlation coefficient reliability.

\section{Data Collection and Analysis}

Data collected from the pre-tests and post-tests were collected for analysis. Students' writings were then collected and coded before being given to the two inter-raters.

Firstly, a paired sample t-test was run to test whether there was any significant difference in the pre-test and post-test's scores of the experimental group. The purposes of this test were to find out whether Facebook-based peer comment activities affects students' writing quality. Secondly, in order examine whether there was any significant difference in the pre-test and post-test's scores of the control group, a paired sample ttest was computed. Finally, research question 2 was answered based on the difference of the test scores in the post-test of the control group and the experimental group. An independent sample T-test was run to analyze the mean difference between the post-test scores of the two groups.

\section{FINDINGS AND DISCUSSION}

As for the first research question of the study regarding whether paper-and-pen peer comment and Facebook-based peer comment activities both significantly improve students' writing quality, the researchers ran Independent Sample T-test to determine whether there was any significant difference in the pre-test scores between the control and the experimental group before the treatment. In case the null hypothesis was not rejected, the study could go further to investigate where the traditional and Facebook- 
based peer comments had any effects on the students' writing quality. Table 1 presents the comparison of the pre-tests of both groups before the peer comment training.

Table 1

Students' Writing Quality before the Treatment

\begin{tabular}{lllllllll}
\hline & Group & $\mathrm{N}$ & $\mathrm{M}$ & $\mathrm{SD}$ & $\mathrm{MD}$ & $t$ & $d f$ & $p$ \\
\hline \multirow{2}{*}{ Pre-test } & Control & 40 & 5.730 & .872 & \multirow{2}{*}{0.173} & \multirow{2}{*}{0.982} & \multirow{2}{*}{69.168} & \multirow{2}{*}{0.329} \\
& Experimental & 32 & 5.903 & .621 & & & & \\
\hline Independent Samples t-test & & & & & & & \\
\hline
\end{tabular}

Table 1 shows the results of the independent sample T-test. The mean score of the control group's pre-test is $\mathrm{M}=5.730(\mathrm{SD}=.872)$ whilst that of the experimental group's pre-test is $\mathrm{M}=5.903(\mathrm{SD}=.621)$. The average pre-test scores of the control group $(\mathrm{M}=$ 5.730; $\mathrm{SD}=.872)$ is lower than that of the experimental group $(\mathrm{M}=5.903 ; \mathrm{SD}=.621)$. The mean difference of the pre-test scores of the two groups is $\mathrm{MD}=-.173$. However, according to the analysis of the independent sample T-test, the pre-test scores of the two groups are not statistically different $(\mathrm{p}=.329)$. Therefore, it can be concluded that there is no statistically significant difference in students' writing quality of the control and the experimental groups before the treatment. This conclusion was the basis for the study to investigate whether there was any different effects of Facebook-based peer comment and traditional peer comment activities on students' writing skills after the treatments.

To determine whether paper-and-pen peer comment activities have any effects on students' writing quality, the researcher computed a paired sample T-test to compare the mean of the pre-test's and post-test's scores of the control group.

Table 2

Paired Samples T-Test

\begin{tabular}{lllllllll}
\hline & Variable & M & Correlation & SD & MD & $t$ & $d f$ & $p$ \\
\hline \multirow{2}{*}{ Control group } & Pre-test & 5.715 & \multirow{2}{*}{.273} & .878 & \multirow{2}{*}{-.78} & -4.399 & \multirow{2}{*}{38} & \multirow{2}{*}{.000} \\
& Post-test & 6.495 & & .955 & -78 & \\
\hline
\end{tabular}

Table 2 illustrates the results of the paired sample T-test. As can be seen from the table, the mean score of the pre-test is $\mathrm{M}=5.715$ ( $\mathrm{SD}=.878$ ) while the mean score of the posttest is $\mathrm{M}=6.495$ ( $\mathrm{SD}=.955)$. The mean difference of the pre-test and the post-test scores of the control group is $\mathrm{MD}=-.78$. The average pre-test score $(\mathrm{M}=5.715, \mathrm{SD}=.878)$ is lower than the average post-test score $(\mathrm{M}=6.495 ; \mathrm{SD}=.955)$, and the Sig. for the comparison of the average scores of the pre-test and post-test is $p=.000$. Hence, the difference in the pre-test and post-test scores of the control group is statistically significant. Consequently, it can be concluded that paper-and-pen peer comment activities have effects on students' writing quality. This result corresponded to previous studies such as Barnard, Luca, and Li (2015), Huisman et al., (2018) who found that students' writing skills improved during the course employing peer comment activities.

To figure out whether Facebook based-peer comment activities affected students' writing quality, a paired sample T-test was calculated to compare the experimental group's mean scores of the pre-test and post-test. 
Table 3

Paired Samples T-Test

\begin{tabular}{lllllllll}
\hline & Variable & $\mathrm{M}$ & Correlation & SD & MD & $t$ & $d f$ & $p$ \\
\hline $\begin{array}{l}\text { Experimental } \\
\text { group }\end{array}$ & Pre-test & 5.903 & .284 & .621 & \multirow{2}{*}{-1.09} & -7.830 & \multirow{2}{*}{31} & \multirow{2}{*}{.000} \\
\hline
\end{tabular}

Table 3 depicts the results of the paired sample T-test. The mean score of the pre-test is $\mathrm{M}=5.903(\mathrm{SD}=.621)$. The mean score of the post-test is $\mathrm{M}=6.994(\mathrm{SD}=.692)$. The average score of the Pre-test $(M=5.903 ; \mathrm{SD}=.621)$ is lower than that of the post-test $(\mathrm{M}=6.994 ; \mathrm{SD}=.692)$. The mean difference of the pre-test and post-test scores of the experimental group is $\mathrm{MD}=-1.09$. The Sig. for the comparison of the average scores of the pre-test and post-test is $\mathrm{p}=.000$. Thus, the difference in the pre-test's and post-test's scores is statistically significant. The analysis of the paired sample T-test indicates that Facebook-based peer comment activities positively affect student's writing quality. This finding supported the conceptual framework of the current study presented in fig. 1 . The result of this study bolsters Ebadi and Rahimi (2017) who indicated that both traditional peer comments and peer e-comments significantly developed the learners' academic writing skills.

The results of the current study confirmed the effects of peer comment or e-comment activities on students writing quality in literature. It indicates that when peer comment activity was well-designed to train the students in the classrooms either with or without technological supports, it remains effective in terms of helping students to enhance their writing skills. The results of the current study were in agreements with previous researchers (Barnard et al. 2015; Huisman et al., 2018; Carless et al., 2011; Sullivan \& Pratt, 1996; and Warschauer, 1997) who conluded that peer comment or e-comment activity engaged students in autonomous learning and become part of the methods of teaching academic writing to develop students' writing skills. Hence, Boud and Molloy (2013) stated that peer comment/e-comment activity should be used as a key role or an instructional tool in the teaching and learning process. McConlogue (2015) suggests that helping students to become peer reviewers is a long-term process and should be withheld to develop students as expertise in the commentary activities. Therefore, decision to employ either peer comments or peer e-comments for teaching and learning activities in the classroom was up to the conditions of the professional contexts where facility for it was available.

So far, the answers to the first research question have indicated that both Facebookbased peer comment activities and paper-and-pen peer comment activities have effects on students' writing quality. As for the second research question of the study regarding whether there is any significant difference between the effects of Facebookbased peer comment and paper-and-pen peer comment activities on students' writing quality, the researchers ran independent sample $\mathrm{T}$-test to analyze the difference in the post-test's scores of the control and the experimental groups. 
Table 4

Independent Samples T-Test

\begin{tabular}{lllllllll}
\hline & Group & $\mathrm{N}$ & $\mathrm{M}$ & SD & MD & $t$ & $d f$ & $p$ \\
\hline \multirow{2}{*}{ Post-test } & Control & 40 & 6.495 & .942 & \multirow{2}{*}{-.499} & -2.501 & \multirow{2}{*}{70} & \multirow{2}{*}{015} \\
& Experimental & 32 & 6.994 & .692 & & & & \\
\hline
\end{tabular}

Table 4 shows the results of the independent sample T-test. As can be seen from Table 4.4 , the mean difference of the control group and experimental group in the post-test is $\mathrm{MD}=-.499$. The students' average post-test score of the experimental group $(\mathrm{M}=6.994$; $\mathrm{SD}=.692)$ is higher than that of the control group $(\mathrm{M}=6.495 ; \mathrm{SD}=.942)$, and the Sig. for the comparison of the average post-test scores of the two groups is $\mathrm{p}=.015<.05$. Thus, the difference in the post-test scores of the experimental and the control groups is statistically significant; therefore, the data analysis results indicate that both Facebookbased peer comment activities and paper-and-pen peer comment activities help improve students' writing quality, but Facebook-based peer comment activities are more effective than the traditional peer comment activities in improving students' writing quality. This result corresponds to Shih (2011), Razak and Saeed (2015), Wichadee (2013), and Suthiwartnarueput \& Wasanasomsithi (2012) that Facebook peer comments helped students improve their writing quality. The theoretical framework/conceptual framework of the study (fig. 1) was bolstered by the findings of this study.

This result is in line with the conclusion reached by Song and Usaha (2009), Sullivan and Pratt (1996), Braine (1997), Ebadi and Rahimi (2017) and Tuzi (2004) that peer ecomments significantly affected the students' writing quality compared to that of the traditional peer comment group. However, the result of the current study contradicted Liu and Sadler's (2003) and Ho's (2015) who found that peer e-comments were less effective than those in the traditional peer comments. Xu's (2007) found that the quality of peer comments in both modes was no significant difference.

More importantly, the fact that Facebook-based peer comments positively affect students' writing quality confirms the results of previous studies on the effects of Facebook-based peer comments on writing quality (Shih, 2011; Suthiwartnarueput \& Wasanasomsithi, 2012; Wichadee, 2013; and Hoang \& Nguyen, 2016). These consistent results about the effectiveness of peer comments on the Facebook platform can be attributed to the features offered by Facebook. They seem to support the view about the benefits of Facebook in earlier studies that Facebook offers considerable opportunities for collaboration because it can encourage learners to create knowledge and take part in the learning process. The findings of the current study provide a great contribution to the body knowledge of literature.

\section{CONCLUSION}

The purpose of the current study was to investigate whether traditional peer comments should be replaced by the peer e-comments. It was evident from the findings that both types of peer comments exchanged via the two modes significantly improved students' writing quality, but the effects of peer e-comments outweighed those of traditional peer 
comments on students' writing quality, and the difference was statistically significant. In a sense, the results of the current study reconfirmed the effectiveness of peer commentary activities on the students' writing quality in either condition of treatments. Whether or not replacement occurs, it depends on the teachers' professional contexts, available facilities, and teachers' comfort of using technology. In case technology was supported to the writing classrooms, peer e-comment activity was a better choice. On the other hand, in case some teachers who were not comfortable employing technology in the writing classrooms, traditional peer comment was still effective to help students enhance their writing quality. This is a notable contribution of this study to the literature that there were few studies comparing the effects of Facebook-based peer comments and paper-and-pen peer comments on the students' writing. Also, the current study obtained good contribution to the literature in terms of employing control and experimental groups while most of the previous studies employed single-group treatment. This finding helps those teachers who waver between choosing Facebook and choosing the traditional mode for peer comment activities to have a suitable choice.

This study offers the following practical implications for L2 writing teachers. First, paper-and pen peer comments activities improve students' writing quality. Writing teachers can apply these in their writing class to motivate their students to participate in writing activities and improve their writing quality, especially when their students do not have regular access to the Internet and do not own a computer. Second, the findings of this study show that Facebook-based peer comment activities significantly improve students' writing quality, and that Facebook-based peer comment activities are more effective than paper-and pen peer comment activities. Thus, if possible, writing teachers can consider replacing the traditional mode by Facebook. These findings enable writing teachers to decide the most suitable platform for peer comment activities for their writing class. If their students have access to modern technology such as the Internet and computers, Facebook-based peer comment activities help them take advantage of available technology to learn to write better. On the contrary, if their students are technophobes and prefer the traditional mode, paper and pen peer comment activities are a reasonable alternative.

\section{REFERENCES}

Badger, R., \& White, G. (2000). A process genre approach to teaching writing. ELT Journal, 54(2), 153-160. https://doi.org/10.1093/elt/54.2.153.

Barnard, R., Luca, R. D., \& Li, J. (2015). First-year undergraduate students' perceptions of lecturer and peer feedback: a New Zealand action research project. Studies in Higher Education, 40(5), 933-944.

Boud, D., \& Molloy, E. (2013). Rethinking models of feedback for learning: the challenge of design. Assessment \& Evaluation in Higher Education, 38(6), 698-712.

Braine, G. (1997). Beyond word processing: Networked computers in ESL writing classes. Computers and Composition, 14(1), 45-58. 
Carless, D., Salter, D., Yang, M., \& Lam, J. (2011). Developing sustainable feedback practices. Studies in Higher Education, 36(4), 395-407.

Chen, T. (2016). Technology-supported peer feedback in ESL/EFL writing classes: A research synthesis. Computer Assisted Language Learning, 29(2), 365-397.

Cohen, L., Manion, L., \& Morrison, K. (2007). Research methods in education. New York: Routledge.

Creswell, J. W. (2009). Research design: Qualitative, quanlitative, and mixed methods approaches. California: SAGE.

Curtis, A. (2001). Hong Kong student teachers' responses to peer group process writing. Asian Journal of English Language Teaching, 11, 129-143.

Dang, T. T. (2010). Learner autonomy in EFL studies in Vietnam: A discussion from sociocultural perspective. English Language Teaching, 3(2), 3-9.

Dizon, G. (2016). A comparative study of Facebook vs. paper-and-pencil writing to improve L2 writing skills. Computer Assisted Language Learning, 29(8), 1249-1258.

Ebadi, S., \& Rahimi, M. (2017). Exploring the impact of online peer-editing using Google Docs on EFL learners' academic writing skills: A mixed methods study. Computer Assisted Language Learning, 30(8), 787-815.

Etikan, I., Musa, S. A., \& Alkassim, N. S. (2016). Comparison of convenience sampling and purposive sampling. American J. of Theoretical and Applied Statistics, 5(1), 1-4.

Ferris, D. (2007). Preparing teachers to respond to student writing. Journal of Second Language Writing, 16(3), 165-193.

Ho, M. C. (2015). The effects of face-to-face and computer-mediated peer review on EFL writers' comments and revisions. Australasian Journal of Educational Technology, 31(1), 1-15.

Ho, M.-C., \& Savignon, S. J. (2007). Face-to-face and computer-mediated peer review in EFL writing. CALICO Journal, 24(2), 269-290.

Hoang, Y. P., \& Nguyen, T. Q. (2016). Effects pf peer feedback on Facebook on high school students' writing performance and attitudes. Exploring New Paths to a Better Future of ELTN in a Globalised World. Ho Chi Minh: Vietnam National University.

Huisman, A., Saab, N., Driel, J. V., \& Broek, P. V. (2018). Peer feedback on academic writing: undergraduate students' peer feedback role, peer feedback perceptions and essay performance. Assessment \& Evaluation in Higher Education, 43(6), 955-968.

Hung, B. P., \& Van, L. T. (2018). Depicting and outlining as pre-writing strategies: Experimental results and learners' opinions. Int. Journal of Instruction, 11(2), 451-464.

Hyland, K. (2016). Methods and methodologies in second language writing. System, 59, 116-125. 
Illowsky, B., \& Dean, S. (2017). Introductory statisticcs. Houston, Texas: OpenStax.

Karim, A., Shahed, F. H., Rahman, M. M., \& Mohamed, A. R. (2019). Revisiting innovations in ELT through online classes: An evaluation of the approaches of 10minute school. Turkish Online Journal of Distance Education, 20(1), 248-266.

Kelsey, S., \& St.Amant, K. (2012). Computer-mediated communication: Issues and approaches in education. Pennsylvania: IGI Global.

Liu, J., \& Hansen, J. G. (2002). Peer response in second language writing classrooms. USA: University of Michigan.

Liu, J., \& Sadler, R. W. (2003). The effect and affect of peer review in electronic versus traditional modes on L2 writing. J. of English for Academic Purposes, 2(3), 193-227.

Majid, A. H., Stapa, S. H., \& Keong, Y. C. (2015). Blended scaffolding strategies through Facebook for learning and improving the writing process and writing performance. e-Bangi, 12(4).

McConlogue, T. (2015). But is it fair? Developing students' understanding of grading complex written work through peer assessment. Studies in Higher Education, 40(9), 1495-1506.

Mendoca, C., \& Johnson, K. (1994). Peer review negotiations: Revision activities in ESL writing instruction. TESOL Quarterly, 28(4), 745-768.

Nguyen, T. H., Fehring, H., \& Warren, W. (2015). EFL teaching and learning at a Vietnamese university: What do teachers say? English Language Teaching, 8, 31-43.

Palmquist, M. (1993). Network-supported interaction in two writing classrooms. Computers and Composition, 14(10), 25-57.

Pham, Vu Phi Ho. (2016). The effects of collaborative writing on individual writing. Journal of Science-Saigon University, 14(39), 67-82.

Pham, V. P. Ho, \& Usaha, S. (2016). Blog-based peer response for 12 writing revision. Computer Assisted Language Learning, 29(4), 724-748.

Pham, V. P. Ho, \& Nguyen, T. Binh. (2014). The effects of communicative grammar teaching on students' achievement of grammatical knowledge and oral production. English Language Teaching (ELT), 7(6), 74-86.

Pham, V. P. Ho. (2019). The effects of lecturer's model e-comments on graduate students' peer e-comments and writing revision. Computer Assisted Language Learning: O9 Jul 2019. https://doi.org/10.1080/09588221.2019.1609521

Pham, V. P. Ho, \& Nguyen, T. T. Hong. (2019). The effects of peer-video recording on students' speaking performance. International J. of English Linguistics, 9(4), 178-191.

Razak, N. A., \& Saeed, M. A. (2015). EFL Arab learners' peer revision of writing in a Facebook group: Contributions to written texts and sense of online community. English Language Teaching, 8(12), 11-26. 
Robson, C., \& Kieran, M. (2016). Real world research. London: John Wiley \& Sons.

Shih, R. C. (2011). Can Web 2.0 technology assist college students in learning English writing? Integrating Facebook and peer assessment with blended learning. Australasian Journal of Educational Technology, 27(5), 829-845.

Song, W., \& Usaha, S. (2009). How EFL university students use electronic peer response into revisions. Suranaree Journal of Science and Technology, 16(3), 263-275.

Statista. (2019, Jan). Leading countries based on number of Facebook users as of January 2019 (in millions). Retrieved March 4, 2019, from The Statistics Portal: https://www.statista.com/statistics/268136/top-15-countries-based-on-number-offacebook-users/

Sullivan, N., \& Pratt, E. (1996). A comparative study of two ESL writing environments: A computer-assisted classroom and a traditional oral classroom. System, 24(4), 491-501.

Suthiwartnarueput, T., \& Wasanasomsithi, P. (2012). Effects of using Facebook as a medium for discussions of English grammar and writing of low-Intermediate EFL students. Electronic Journal of Foreign Language Teaching, 9(2), 194-214.

Thanh Nien News. (2015). Retrieved from Vietnam's Facebook users jump to 30 million: on June 21, 2015, http://www.thanhniennews.com/tech/vietnams-facebookusers-jump-to-30-million-46876.html

Tuzi, F. (2004). The impact of e-feedback on the revisions of L2 writers in an academic writing course. Computers and Composition, 21(2), 217-235.

Warschauer, M. (1997). Computer-mediated collaborative learning: Theory and practice. The Modern Language Journal, 81(4), 470-481.

Wichadee, S. (2013). Peer feedback on Facebook: The use of social networking websites to develop writing ability of undergraduate students. Turkish Online Journal of Distance Education, 14(4), 260-270.

$\mathrm{Xu}, \mathrm{Y}$. (2007). Re-examining the effects and affects of electronic peer reviews in a firstyear composition. The Reading Matrix, 7, 1-21.

Yusof, J., Manan, N., Alias, A. A., \& Pandian, A. (2012). Guided peer feedback via Facebook Notes for mixed-ability ESL learners in the Process Writing classroom: An Exploratory Study. Voice of Academia, 7(1), 14-33.

Zen, D. (2005). The process approach to ESL/EFL writing. The Journal of Asia TEFL, 2, 191-198.

Zuckerberg, M. (2018). Company info. Retrieved from Facebook Newsrooms: https://newsroom.fb.com/company-info/. 